Advertisement

\title{
Social Aspects of HIV
}

Springer Social Sciences

Springer

springer.com

Springer Link

Search $Q$

- Login

Menu

- Login

Search SpringerLink

Search $Q$

- Published: 04 March 2019

\section{Does inappropriate prescribing affect elderly patients' quality of life? A study from a Malaysian tertiary hospital}

- Muhammad Eid Akkawi ORCID: orcid.org/0000-0001-9964-0355는,

- Mohamad Haniki Nik Mohamed $\square 1$ \&

- Mohd Aznan Md Aris $\underline{2}$

Quality of Life Research volume 28, pages1913-1920(2019)Cite this article

- 190 Accesses

- 1 Citations

- 1 Altmetric

- Metrics details

\section{Abstract}

\section{Purpose}

To investigate the association between potentially inappropriate medication (PIM)/potential prescribing omission (PPO) and the health-related quality of life (HRQoL) among community-dwelling hospitalized elderly patients.

\section{Methods}

This is a cross-sectional study that took place in a Malaysian tertiary hospital. Patients $\geq 65$ years old with at least one medication on admission were recruited. The patients' prehospitalization medications were reviewed to identify PIMs/PPOs using version 2 of the STOPP/START criteria. HRQoL was assessed using the EuroQol-5 dimensions (EQ-5D) and EuroQolvisual analog scale (EQ-VAS). The association between the presence of PIM/PPO and the patients' HRQoL was analyzed using Chi-square and Mann-Whitney $\mathrm{U}$ tests. Multiple linear regression models were applied to determine the effect of exposure to PIM/PPO on the patients' HRQoL, adjusting for confounders.

\footnotetext{
We use cookies to personalise content and ads, to provide social media features and to analyse our traffic. We also share information about your use of our site with our social media, advertising and analytics partners in accordance with our 
differences were found in the EQ-5D dimensions, EQ-5D index and EQ-VAS between patients who had PIM/PPO and those who did not. Age, sex, and comorbidities were significantly associated with the patients' HRQoL.

\section{Conclusion}

PIM and PPO are not uncommon among hospitalized elderly patients; however, it does not significantly affect their HRQoL as measured by the EQ-5D-3L instrument.

This is a preview of subscription content, log in to check access.

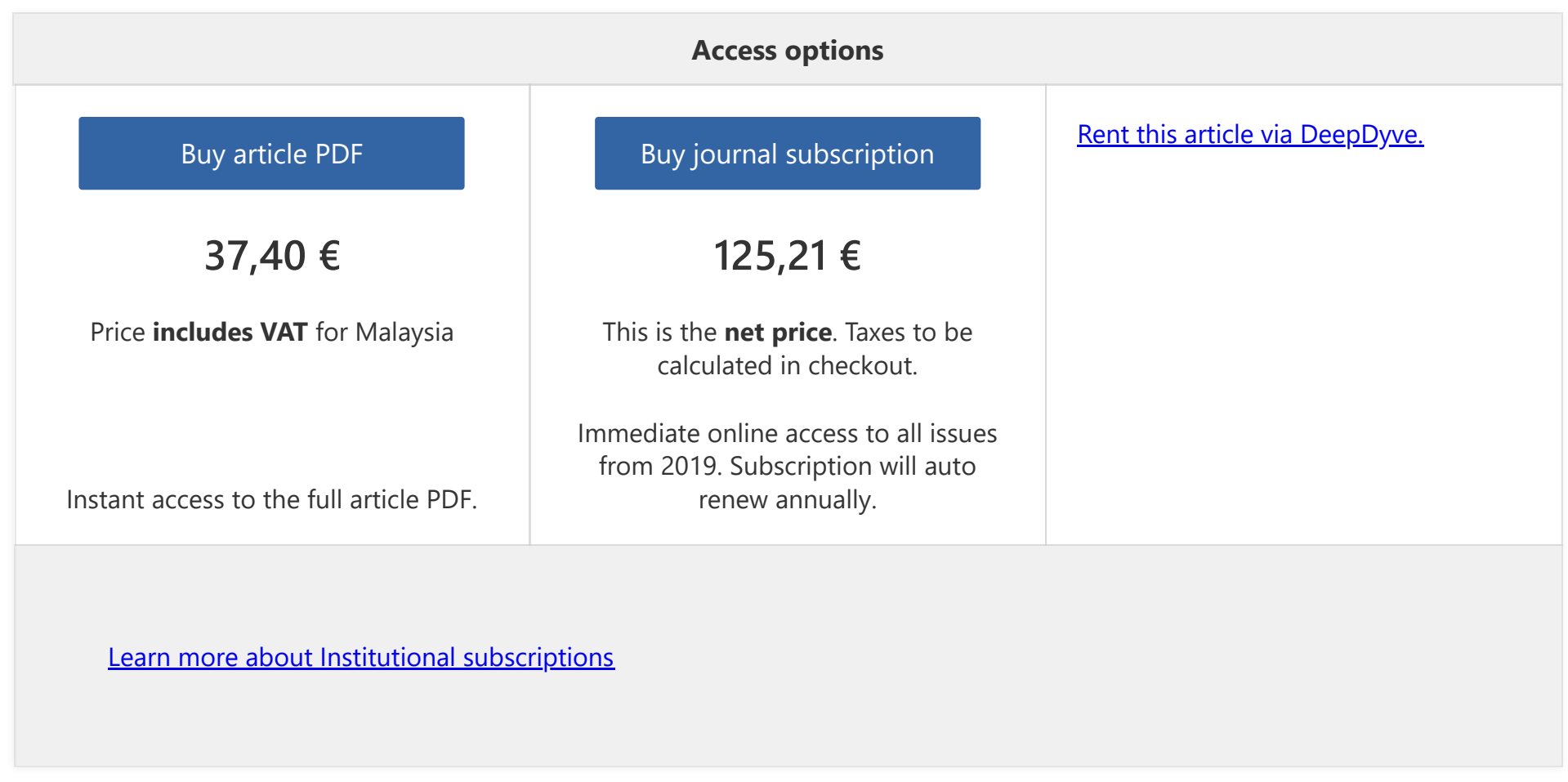

\section{References}

1. 1.

Nordin Olsson, I., Runnamo, R., \& Engfeldt, P. (2011). Medication quality and quality of life in the elderly, a cohort study. Health and Quality of Life Outcomes, 9(1), 95. https://doi.org/10.1186/1477-7525-9-95.

- Article

- PubMed Central

- Google Scholar

2. 2.

Karimi, M., \& Brazier, J. (2016). Health, Health-related quality of life, and quality of life: What is the difference? PharmacoEconomics, 34(7), 645-649. https://doi.org/10.1007/s40273-016-0389-9.
- Article
- PubMed
- Google Scholar

3. 3.

Franic, D. M., \& Jiang, J. Z. (2006). Potentially inappropriate drug use and health-related quality of life in the elderly.

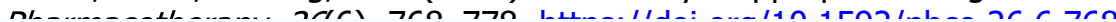

We use cookies to personalise content and ads, to provide social media features and to analyse our traffic. We also share information about your use of our site with our social media, advertising and analytics partners in accordance with our

Privacy Statement. You can manage your preferences in Manage Cookies. 
Kaplan, R. M. (2003). The significance of quality of life in health care. In Quality of life research (Vol. 12, pp. 3-16). Dordrecht: Kluwer Academic Publishers. https://doi.org/10.1023/A:1023547632545.

5. 5.

Rolfes, L., van Hunsel, F., Taxis, K., \& van Puijenbroek, E. (2016). The Impact of experiencing adverse drug reactions on the patient's quality of life: A retrospective cross-sectional study in the Netherlands. Drug Safety, 39(8), 769-776. https://doi.org/10.1007/s40264-016-0422-0.

- Article

- CAS

- PubMed

- PubMed Central

- Google Scholar

6. 6.

O'Connor, M. N., Gallagher, P., \& O'Mahony, D. (2012). Inappropriate prescribing: Criteria, detection and prevention. Drugs \& Aging, 29(6), 437-452. https://doi.org/10.2165/11632610-000000000-00000.

- Article

7. 7.

- Google Scholar

Hamilton, H., Gallagher, P., Ryan, C., Byrne, S., \& O'Mahony, D. (2011). Potentially inappropriate medications defined by STOPP criteria and the risk of adverse drug events in older hospitalized patients. Archives of Internal Medicine, 171(11), 1013-1019. https://doi.org/10.1001/archinternmed.2011.215.

- Article

- PubMed

- Google Scholar

8. 8.

van der Stelt, C. A. K., Windsant-van den Tweel, A. M. A., Egberts, A. C. G., Van den Bemt, P. M. L. A., Leendertse, A. J., Hermens, W. A. J. J., Derijks, H. J. (2016). The association between potentially inappropriate prescribing and medication-related hospital admissions in older patients: A nested case control study. Drug Safety, 39(1), $79-87$. https://doi.org/10.1007/s40264-015-0361-1.

- Article

- PubMed

- Google Scholar

9. 9.

Wallace, E., McDowell, R., Bennett, K., Fahey, T., \& Smith, S. M. (2017). Impact of potentially inappropriate prescribing on adverse drug events, health related quality of life and emergency hospital attendance in older people attending general practice: A prospective cohort study. The Journals of Gerontology. Series A, Biological Sciences and Medical Sciences, 72(2), 271-277. https://doi.org/10.1093/gerona/glw140.

10. 10.

- Article

- PubMed

- Google Scholar

Meid, A. D., Quinzler, R., Groll, A., Wild, B., Saum, K. U., Schöttker, B., Haefeli, W. E. (2016). Longitudinal evaluation of medication underuse in older outpatients and its association with quality of life. European Journal of Clinical

Pharmacology, 72(7), 877-885. https://doi.org/10.1007/s00228-016-2047-8.

- Article

We use cookies to personalise content and ads, to provide social media features and to analyse our traffic. We also share information about your use of our site with our social media, advertising and analytics partners in accordance with our

Privacy Statement. You can manage your preferences in Manage Cookies. 
$\circ$ Article

- PubMed

- PubMed Central

- Google Scholar

12. 12.

Al Aqqad, S. M. H., Chen, L. L., Shafie, A. A., Hassali, M. A., \& Tangiisuran, B. (2014). The use of potentially inappropriate medications and changes in quality of life among older nursing home residents. Clinical Interventions in Aging, 9, 201-207. https://doi.org/10.2147/CIA.S52356.

13. 13.

- Article

- PubMed

- Google Scholar

Lim, L. M., McStea, M., Chung, W. W., Azmi, N. N., Aziz, S. A. A., Alwi, S., Rajasuriar, R. (2017). Prevalence, risk factors and health outcomes associated with polypharmacy among urban community-dwelling older adults in multiethnic Malaysia. PLoS ONE, 12(3), 1-18. https://doi.org/10.1371/journal.pone.0173466.

- CAS

- Article

- Google Scholar

14. 14.

Najjar, M. F., AbdulRazzaq, H. A., Altaie, A. H., Kassab, Y. W., Hassan, Y., \& Abd Aziz, N., (2013). Assessment of potentially inappropriate medications and risk of drug-drug interactions among geriatric inpatients in Penang Hospital. International Journal of Clinical Pharmacy (Vol, 35, 911-912.

- Google Scholar

15. 15.

Population distribution and basic demographic characteristic report. (2011). Retrieved from https://www.dosm.gov.my/v1/index.php?

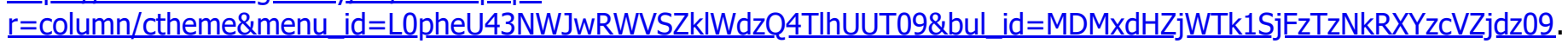

16. 16.

Naing, L., Winn, T., \& Rusli, B. N. (2006). Practical issues in calculating the sample size for prevalence studies. Archives of Orofacial Sciences, 1, 9-14. http://citeseerx.ist.psu.edu/viewdoc/download? doi=10.1.1.504.2129\&rep=rep1\&type=pdf.

17. 17.

Charlson, M., Szatrowski, T. P., Peterson, J., \& Gold, J. (1994). Validation of a combined comorbidity index. Journal of Clinical Epidemiology, 4オ11), 1245-1251. https://doi.org/10.1016/0895-4356(94)90129-5.

- Article

- $\underline{\text { CAS }}$

- PubMed

- Google Scholar

18. 18.

O'Mahony, D., O'Sullivan, D., Byrne, S., O'Connor, M. N., Ryan, C., \& Gallagher, P. (2015). STOPP/START criteria for potentially inappropriate prescribing in older people: Version 2. Age and Ageing, 44(2), 213-218.

https://doi.org/10.1093/ageing/afu145.

$\circ$ Article

We use cookies to personalise content and ads, to provide social media features and to analyse our traffic. We also share information about your use of our site with our social media, advertising and analytics partners in accordance with our

Privacy Statement. You can manage your preferences in Manage Cookies. 
20. 20.

$\circ$ Article

- PubMed

- Google Scholar

Rabin, R., \& Charro, F., \& De (2001). EQ-SD: A measure of health status from the EuroQol Group. Annals of Medicine, 33(5), 337-343. https://doi.org/10.3109/07853890109002087.

21. 21.
- Article
- CAS
- PubMed
- Google Scholar

Md Yusof, F. A., Goh, A., \& Azmi, S. (2012). Estimating an EQ-5D value set for malaysia using time trade-off and visual analogue scale methods. Value in Health, 15(1 SUPPL.), S85-S90. https://doi.org/10.1016/j.jval.2011.11.024.
- Article
- Google Scholar

22. 22.

Shafie, A. A., Hassali, M. A., \& Liau, S. Y. (2011). A cross-sectional validation study of EQ-5D among the Malaysian adult population. Quality of Life Research, 20(4), 593-600. https://doi.org/10.1007/s11136-010-9774-6.
- Article
- PubMed
- Google Scholar

23. 23.

Wolfs, C. A. G., Dirksen, C. D., Kessels, A., Willems, D. C. M., Verhey, F. R. J., \& Severens, J. L. (2007). Performance of the EQ-5D and the EQ-5D+C in elderly patients with cognitive impairments. Health and Quality of Life Outcomes, 5(33). https://doi.org/10.1186/1477-7525-5-33.

24. 24.

Cavrini, G., Broccoli, S., Puccini, A., \& Zoli, M. (2012). EQ-5D as a predictor of mortality and hospitalization in elderly people. Quality of Life Research, 21(2), 269-280. https://doi.org/10.1007/s11136-011-9937-0.

25. 25.
$\circ$ Article
- PubMed
- Google Scholar

Mangen, M. J. J., Bolkenbaas, M., Huijts, S. M., van Werkhoven, C. H., Bonten, M. J. M., \& de Wit, G. A. (2017). Quality of life in community-dwelling Dutch elderly measured by EQ-5D-3L. Health and Quality of Life Outcomes, 15(1), 3. https://doi.org/10.1186/s12955-016-0577-5.

26. 26.
- Article
- PubMed
- PubMed Central
- Google Scholar

Clemens, S., Begum, N., Harper, C., Whitty, J. A., \& Scuffham, P. A. (2014). A comparison of EQ-5D-3L population norms in Queensland, Australia, estimated using utility value sets from Australia, the UK and USA. Quality of Life Research: An International Journal of Quality of Life Aspects of Treatment, Care and Rehabilitation, 23(8), $2375-2381$. https://doi.orq/10.1007/s11136-014-0676-x.

\footnotetext{
We use cookies to personalise content and ads, to provide social media features and to analyse our traffic. We also share information about your use of our site with our social media, advertising and analytics partners in accordance with our

Privacy Statement. You can manage your preferences in Manage Cookies.
} 
$\circ$ Article

- PubMed

- PubMed Central

- Google Scholar

28. 28.

Perneger, T. V., Combescure, C., \& Courvoisier, D. S. (2010). General population reference values for the french version of the euroqol EQ-5D health utility instrument. Value in Health, 13(5), 631-635. https://doi.org/10.1111/j.15244733.2010.00727.x.

- Article

- PubMed

29. 29.

- Google Scholar

Fu, A. Z., Liu, G. G., \& Christensen, D. B. (2004). Inappropriate medication use and health outcomes in the elderly. Journal of the American Geriatrics Society, 52(11), 1934-1939. https://doi.org/10.1111/j.1532-5415.2004.52522.x.

- Article

- PubMed

- Google Scholar

Download references $\underline{\underline{ }}$

\section{Funding}

This study was funded by the International Islamic University Malaysia (IIUM) Research Initiative Grant Scheme (No. RIGS 15- 098-0098).

\section{Author information}

\section{Affiliations}

1. Department of Pharmacy Practice, Faculty of Pharmacy, International Islamic University Malaysia (IIUM), Kuantan, Malaysia

- Muhammad Eid Akkawi

- \& Mohamad Haniki Nik Mohamed

2. Department of Family Medicine \& Non-Communicable Disease Research Unit, Faculty of Medicine, International Islamic University Malaysia (IIUM), Kuantan, Malaysia

- Mohd Aznan Md Aris

Authors

1. Muhammad Eid Akkawi

View author publications

You can also search for this author in

- PubMed

- Google Scholar

2. Mohamad Haniki Nik Mohamed

View author publications

You can also search for this author in

- PubMed

- Google Scholar

3. Mohd Aznan Md Aris

linus, arithon nuihlientinne

We use cookies to personalise content and ads, to provide social media features and to analyse our traffic. We also share information about your use of our site with our social media, advertising and analytics partners in accordance with our

Privacy Statement. You can manage your preferences in Manage Cookies. 


\section{Ethics declarations}

\section{Conflict of interest}

The authors declare that they have no conflict of interest.

\section{Ethical approval}

The study was conducted in accordance with the guidelines of the 1964 Helsinki declaration and its later amendments. Ethical approval was obtained from the Medical Research and Ethics Committee, Ministry of Health Malaysia (No. NMRR-15-71825235), and from the Clinical Research Center (CRC) of the HTAA hospital.

\section{Additional information}

\section{Publisher's Note}

Springer Nature remains neutral with regard to jurisdictional claims in published maps and institutional affiliations.

\section{Rights and permissions}

Reprints and Permissions

\section{About this article}

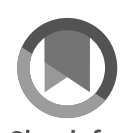

Check for

updates

\section{Cite this article}

Akkawi, M.E., Nik Mohamed, M.H. \& Md Aris, M.A. Does inappropriate prescribing affect elderly patients' quality of life? A study from a Malaysian tertiary hospital. Qual Life Res 28, 1913-1920 (2019). https://doi.org/10.1007/s11136-019-02153-5

\section{Download citation $\underline{\underline{ }}$}

- Accepted: 25 February 2019

- Published: 04 March 2019

- Issue Date: 15 July 2019

- DOI: https://doi.org/10.1007/s11136-019-02153-5

\section{Keywords}

- Potentially inappropriate prescribing

- Health-related quality of life

- Elderly patients

- Hospitalization

- EQ-5D-3L

We use cookies to personalise content and ads, to provide social media features and to analyse our traffic. We also share information about your use of our site with our social media, advertising and analytics partners in accordance with our Privacy Statement. You can manage your preferences in Manage Cookies. 


\section{$37,40 €$ \\ Price includes VAT for Malaysia}

Instant access to the full article PDF.

\section{Buy journal subscription}

\section{$125,21 €$}

This is the net price. Taxes to be calculated in checkout.

Immediate online access to all issues from 2019. Subscription will auto renew annually.

Rent this article via DeepDyve.

\section{Learn more about Institutional subscriptions}

- Sections

- References

- Abstract

- References

- Funding

- Author information

- Ethics declarations

- Additional information

- Rights and permissions

- About this article

\section{Advertisement}

1. Nordin Olsson, I., Runnamo, R., \& Engfeldt, P. (2011). Medication quality and quality of life in the elderly, a cohort study. Health and Quality of Life Outcomes, $9(1), 95$.

https://doi.org/10.1186/1477-7525-9-95.

- Article

- PubMed Central

- Google Scholar

2. Karimi, M., \& Brazier, J. (2016). Health, Healthrelated quality of life, and quality of life: What is the difference? PharmacoEconomics, 34(7), 645649. https://doi.org/10.1007/s40273-016-0389-

We use cookies to personalise content and ads, to provide social media features and to analyse our traffic. We also share information about your use of our site with our social media, advertising and analytics partners in accordance with our Privacy Statement. You can manage your preferences in Manage Cookies. 
of life in the elderly. Pharmacotherapy, 26(6),

768-778. https://doi.org/10.1592/phco.26.6.768.

- Article

- PubMed

- Google Scholar

4. Kaplan, R. M. (2003). The significance of quality of life in health care. In Quality of life research (Vol. 12, pp. 3-16). Dordrecht: Kluwer Academic Publishers. https://doi.org/10.1023/A:1023547632545.

5. Rolfes, L., van Hunsel, F., Taxis, K., \& van Puijenbroek, E. (2016). The Impact of experiencing adverse drug reactions on the patient's quality of life: A retrospective crosssectional study in the Netherlands. Drug Safety, 39(8), 769-776. https://doi.org/10.1007/s40264016-0422-0.
- Article
- CAS
- PubMed
- PubMed Central
- Google Scholar

6. O'Connor, M. N., Gallagher, P., \& O’Mahony, D. (2012). Inappropriate prescribing: Criteria, detection and prevention. Drugs \& Aging, 296), 437-452. https://doi.org/10.2165/11632610000000000-00000.

- Article

- Google Scholar

7. Hamilton, H., Gallagher, P., Ryan, C., Byrne, S., \& O'Mahony, D. (2011). Potentially inappropriate medications defined by STOPP criteria and the risk of adverse drug events in older hospitalized patients. Archives of Internal Medicine, 171(11), 1013-1019.

https://doi.org/10.1001/archinternmed.2011.215.
- Article
- PubMed
- Google Scholar

8. van der Stelt, C. A. K., Windsant-van den Tweel, A. M. A., Egberts, A. C. G., Van den Bemt, P. M. L. A., Leendertse, A. J., Hermens, W. A. J. J., Derijks, H. J. (2016). The association between potentially inappropriate prescribing and medication-related hospital admissions in older patients: A nested case control study. Drug Safety, 39(1), 79-87.

\footnotetext{
We use cookies to personalise content and ads, to provide social media features and to analyse our traffic. We also share information about your use of our site with our social media, advertising and analytics partners in accordance with our Privacy Statement. You can manage your preferences in Manage Cookies.
} 
inappropriate prescribing on adverse drug

events, health related quality of life and

emergency hospital attendance in older people

attending general practice: A prospective cohort

study. The Journals of Gerontology. Series A,

Biological Sciences and Medical Sciences, 72(2), 271-277.

https://doi.org/10.1093/gerona/glw140.

- Article

- PubMed

- Google Scholar

10. Meid, A. D., Quinzler, R., Groll, A., Wild, B., Saum, K. U., Schöttker, B., Haefeli, W. E. (2016). Longitudinal evaluation of medication underuse in older outpatients and its association with quality of life. European Journal of Clinical Pharmacology, 72(7), 877-885. https://doi.org/10.1007/s00228-016-2047-8.

- Article

- PubMed

- Google Scholar

11. Moriarty, F., Bennett, K., Cahir, C., Kenny, R. A., \& Fahey, T. (2016). Potentially inappropriate prescribing according to STOPP and START and adverse outcomes in community-dwelling older people: a prospective cohort study. British Journal of Clinical Pharmacology, 82, 849-857. https://doi.org/10.1111/bcp.12995.

- Article

- PubMed

- PubMed Central

- Google Scholar

12. Al Aqqad, S. M. H., Chen, L. L., Shafie, A. A., Hassali, M. A., \& Tangiisuran, B. (2014). The use of potentially inappropriate medications and changes in quality of life among older nursing home residents. Clinical Interventions in Aging, 9, 201-207. https://doi.org/10.2147/CIA.S52356.

- Article

- PubMed

- Google Scholar

13. Lim, L. M., McStea, M., Chung, W. W., Azmi, N. N., Aziz, S. A. A., Alwi, S., Rajasuriar, R. (2017). Prevalence, risk factors and health outcomes associated with polypharmacy among urban community-dwelling older adults in multiethnic Malaysia. PLOS ONE, 12(3), 1-18.

We use cookies to personalise content and ads, to provide social media features and to analyse our traffic. We also share information about your use of our site with our social media, advertising and analytics partners in accordance with our Manage Cookies. 
(2013). Assessment of potentially inappropriate medications and risk of drug-drug interactions among geriatric inpatients in Penang Hospital. International Journal of Clinical Pharmacy ( Vol, 35, 911-912.

- Google Scholar

15. Population distribution and basic demographic characteristic report. (2011). Retrieved from https://www.dosm.gov.my/v1/index.php?

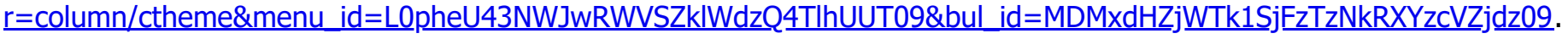

16. Naing, L., Winn, T., \& Rusli, B. N. (2006).

Practical issues in calculating the sample size for prevalence studies. Archives of Orofacial Sciences, 1, 9-14. http://citeseerx.ist.psu.edu/viewdoc/download?

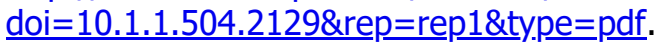

17. Charlson, M., Szatrowski, T. P., Peterson, J., \& Gold, J. (1994). Validation of a combined comorbidity index. Journal of Clinical Epidemiology, 47(11), 1245-1251. https://doi.org/10.1016/0895-4356(94)

- Article

- CAS

- PubMed

- Google Scholar

18. O'Mahony, D., O'Sullivan, D., Byrne, S., O'Connor, M. N., Ryan, C., \& Gallagher, P. (2015). STOPP/START criteria for potentially inappropriate prescribing in older people: Version 2. Age and Ageing, 44(2), 213-218.

https://doi.org/10.1093/ageing/afu145.
- Article
- PubMed
- Google Scholar

19. Gnjidic, D., Hilmer, S. N., Blyth, F. M., Naganathan, V., Waite, L., Seibel, M. J., Le Couteur, D. G. (2012). Polypharmacy cutoff and outcomes: Five or more medicines were used to identify community-dwelling older men at risk of different adverse outcomes. Journal of Clinical Epidemiology, 65(9), 989-995. https://doi.org/10.1016/j:jclinepi.2012.02.018.

- Article

- PubMed

- Google Scholar

20. Rabin, R., \& Charro, F., \& De (2001). EQ-SD: A

\footnotetext{
Rabin, R, \& Charro, Fa, \& De (2001). EQ-SD

We use cookies to personalise content and ads, to provide social media features and to analyse our traffic. We also share information about your use of our site with our social media, advertising and analytics partners in accordance with our Privacy Statement. You can manage your preferences in Manage Cookies.
} 
21. Md Yusof, F. A., Goh, A., \& Azmi, S. (2012). Estimating an EQ-5D value set for malaysia using time trade-off and visual analogue scale methods. Value in Health, 15(1 SUPPL.), S85S90. https://doi.org/10.1016/j:jval.2011.11.024.

- Article

- Google Scholar

22. Shafie, A. A., Hassali, M. A., \& Liau, S. Y. (2011). A cross-sectional validation study of EQ-5D among the Malaysian adult population. Quality of Life Research, 20(4), 593-600.

https://doi.org/10.1007/s11136-010-9774-6.

- Article

- PubMed

- Google Scholar

23. Wolfs, C. A. G., Dirksen, C. D., Kessels, A., Willems, D. C. M., Verhey, F. R. J., \& Severens, J. L. (2007). Performance of the EQ-5D and the $\mathrm{EQ}-5 \mathrm{D}+\mathrm{C}$ in elderly patients with cognitive impairments. Health and Quality of Life Outcomes, 5(33). https://doi.org/10.1186/14777525-5-33.

24. Cavrini, G., Broccoli, S., Puccini, A., \& Zoli, M. (2012). EQ-5D as a predictor of mortality and hospitalization in elderly people. Quality of Life Research, 21(2), 269-280. https://doi.org/10.1007/s11136-011-9937-0.
- Article
- PubMed
- Google Scholar

25. Mangen, M. J. J., Bolkenbaas, M., Huijts, S. M., van Werkhoven, C. H., Bonten, M. J. M., \& de Wit, G. A. (2017). Quality of life in communitydwelling Dutch elderly measured by EQ-5D-3L. Health and Quality of Life Outcomes, 15(1), 3. https://doi.org/10.1186/s12955-016-0577-5.
- Article
- PubMed
- PubMed Central
- Google Scholar

26. Clemens, S., Begum, N., Harper, C., Whitty, J. A., \& Scuffham, P. A. (2014). A comparison of EQ-5D-3L population norms in Queensland, Australia, estimated using utility value sets from Australia, the UK and USA. Quality of Life Research: An International Journal of Quality of Life Aspects of Treatment, Care and

\footnotetext{
We use cookies to personalise content and ads, to provide social media features and to analyse our traffic. We also share information about your use of our site with our social media, advertising and analytics partners in accordance with our

Privacy Statement. You can manage your preferences in Manage Cookies.
} 
H., Alonso, J. (2010). Health status of the

advanced elderly in six european countries:

Results from a representative survey using EQ-

5D and SF-12. Health and Quality of Life

Outcomes, $8(1), 143$.

https://doi.org/10.1186/1477-7525-8-143.
- Article
- PubMed
- PubMed Central
- Google Scholar

28. Perneger, T. V., Combescure, C., \& Courvoisier, D. S. (2010). General population reference values for the french version of the euroqol EQ5D health utility instrument. Value in Health, 13(5), 631-635. https://doi.org/10.1111/j.15244733.2010.00727.x.
- Article
- PubMed
- Google Scholar

29. Fu, A. Z., Liu, G. G., \& Christensen, D. B. (2004). Inappropriate medication use and health outcomes in the elderly. Journal of the American Geriatrics Society, 52(11), 1934-1939.

https://doi.org/10.1111/j.1532-

5415.2004.52522.x.

- Article

- PubMed

- Google Scholar

Over 10 million scientific documents at your fingertips

\section{Switch Edition}

- Academic Edition

- Corporate Edition

- Home

- Impressum

- Legal information

- Privacy statement

- How we use cookies

- Accessibility.

- Contact us

Not logged in - 210.195.109.193

Not affiliated

\section{Springer Nature SPRINGER NATURE}

(C) 2020 Springer Nature Switzerland AG. Part of Springer Nature.

\footnotetext{
We use cookies to personalise content and ads, to provide social media features and to analyse our traffic. We also share information about your use of our site with our social media, advertising and analytics partners in accordance with our Manage Cookies.
} 
We use cookies to personalise content and ads, to provide social media features and to analyse our traffic. We also share information about your use of our site with our social media, advertising and analytics partners in accordance with our Privacy Statement. You can manage your preferences in Manage Cookies. 